\title{
La aplicación de la doctrina del public trust en Estados Unidos: de la protección de los bienes comunes a la conservación del medio ambiente
}

\author{
The application of the Public Trust Doctrine in United States: \\ the protection of the commons and the conservation of the \\ environment
}

MARCOS DE ARMENTERAS CABOT

\begin{abstract}
Resumen: En la protección de los bienes comunes en Estados Unidos desde el siglo XIX hasta la actualidad, la doctrina del public trust ha jugado un papel determinante. Esta doctrina, heredera de la tradición jurídica romana, que basa su estructura conceptual en una relación fideicomisaria entre agente y principal, fue inicialmente invocada para la salvaguarda de los bienes comunes de su cercamiento y privatización. Con el paso de los años, se ha transformado en un instrumento jurídico clave para la protección ambiental. En este artículo doy cuenta de su evolución y aplicación actual.

Palabras clave: doctrina del fideicomiso público, bienes comunes, relación fiduciaria, litigio ambiental en Estados Unidos, conservación ambiental.
\end{abstract}

\begin{abstract}
In the protection of the commons in the United States from the 19th century to the present, the public trust doctrine has played a determining role. This doctrine, inheriting from the Roman legal tradition, bases its conceptual structure on a trust relationship between agent and principal, and it was initially invoked to safeguard the common property from its enclosure and privatization. Over the years, it has become a key legal instrument for environmental protection. In this article I give an account of its evolution and current application.
\end{abstract}

Keywords: public trust doctrine, commons, fiduciary relationship, environmental litigation in the United States, environmental conservation.

Recibido: 31/05/2020. Aceptado: 18/06/2020. Cómo citar este articulo: De Armenteras, M. (2020). La aplicación de la doctrina del public trust en Estados Unidos: de la protección de los bienes comunes a la conservación del medio ambiente. Daimon. Revista Internacional de Filosofía, (81), 131-143. https://doi.org/10.6018/daimon.426551

* Doctorando en la Universitat Rovira i Virgili; Miembro del Centre d'Estudis de Dret Ambiental de Tarragona (CEDAT); Máster en Derecho Ambiental (Universidad del País Vasco); Máster en Sociología Jurídica (Instituto Internacional de Sociología Jurídica de Oñati); Licenciado en Derecho (Universitat de Barcelona); Líneas de Investigación: filosofía política, filosofía y sociología del derecho, ética ambiental y justicia intergeneracional. (Contacto: marcosdearmenteras@gmail.com). Este trabajo ha sido desarrollado dentro del proyecto de investigación Constitución climática global: gobernanza y Derecho en un contexto complejo, financiado por el Ministerio de Economía y Competitividad para el trienio 2017-2019 (proyecto DER2016-80011-P; investigadores principales: Jordi Jaria-Manzano y Susana Borràs Pentinat). El autor quiere agradecer a los dos revisores anónimos que aportaron valiosos comentarios y ayudaron a mejorar este texto. 


\section{Introducción}

Los problemas relacionados con la propiedad de los bienes comunes ocupan un lugar central en las reflexiones contemporáneas acerca de la relación entre propiedad, libertad y democracia. En un estudio sobre la concepción de propiedad como piedra angular del proyecto republicano es conveniente dar cuenta del desarrollo jurisprudencial que ha tenido la doctrina del public trust, para evaluar su importancia en la protección de bienes comunes y su vigencia como mecanismo de protección del medio ambiente. Si bien es cierto que la doctrina ha sido aplicada en otros países herederos del derecho anglosajón, el desarrollo doctrinal y jurisprudencial que se ha dado en Estados Unidos es mucho más extenso e influyente.

Dos hitos marcan el desarrollo de la doctrina en la jurisprudencia estadunidense. El primero deriva de la sentencia del Tribunal Supremo en el caso Illinois Central Railroad v. Illinois, y el segundo deriva de la publicación del artículo del profesor Joseph Sax en 1970 sobre la idoneidad de utilizar la doctrina en los litigios ambientales.

En el año 1869, la Asamblea General de Illinois otorgó a la compañía ferroviaria Illinois Central Railroad la titularidad de las tierras sumergidas en una extensa área del puerto de Chicago en el Lago Michigan. En 1973, el nuevo legislador, derogó el acto de 1869, revocando la concesión otorgada previamente y reclamó ante los tribunales los derechos propiedad de estas mismas tierras. El caso llegó hasta el Tribunal Supremo de Estados Unidos que sentenció que el legislador de 1869 no tenía competencias para ceder a una empresa privada el derecho sobre el puerto de Chicago, pues se trataba de un fideicomiso público - public trust- del que el Estado de Illinois era fiduciario y, en virtud de su soberanía, lo debía conservar y proteger en favor del público ${ }^{1}$. A pesar de que la doctrina del public trust ya había sido aplicada por los tribunales estadounidenses a lo largo del siglo XIX para salvaguardar el interés público de la privatización de infraestructuras públicas relevantes en favor de empresas privadas (Kaplan, 2012, 3-4), la sentencia en el caso Illinois Central fue el primer hito determinante para el desarrollo jurisprudencial de la doctrina.

A partir de esta, el segundo hito clave para el desarrollo de la doctrina deriva de la publicación del artículo del profesor Joseph Sax en 1970 sobre la idoneidad de su aplicación en litigios ambientales y su relevancia en el incipiente derecho ambiental (Sax, 1970). En este sentido, durante los años sesenta y setenta, al calor de las protestas en favor de la justicia ambiental en Estados Unidos y del impacto de los primeros textos de la ecología moderna, se comenzaron a sentar las bases del derecho ambiental. Mientras que la protección jurídica de la base biofísica en la que los seres humanos desarrollan su existencia nunca había sido una preocupación mayor, a partir de los procesos de degradación ambiental y destrucción de los ecosistemas, y el aumento de los riesgos derivados de los desarrollos tecnológicos, la regulación jurídica sobre asuntos ambientales comienza a alcanzar todos los ámbitos de la vida social. En este contexto, Joseph Sax (1936-2014), profesor de la Universidad de Berkeley, planteó la posibilidad de utilizar la doctrina del public trust como un instrumento central en la intervención judicial para promover una mejor gestión y protección de los recursos naturales.

Un hilo conecta la noción de propiedad como un fideicomiso, propio de la tradición republicana y sostenida por el derecho constitucional democrático de entreguerras, con la

1 Tribunal Supremo de Estados Unidos: Illinois Central Railroad v. Illinois, 146 U.S. 387 (1892) 
protección de los bienes comunes a través del instrumento del public trust. A pesar de que la aplicación de la doctrina se ha transformado a lo largo de los dos últimos siglos, la argumentación subyacente sigue asentándose en una relación fiduciaria.

En este texto analizo la relación fiduciaria contenida en la public trust doctrine y el modo en cómo su aplicación a lo largo de los siglos ha modificado su alcance, pero no su estructura normativa. A partir del desarrollo de la concepción de propiedad republicana, daré cuenta de la argumentación jurídica llevada a cabo para conservar y proteger los bienes comunes para uso público de las presentes y futuras generaciones. Para ello, en primer lugar analizaré la noción de bienes comunes y su protección jurídica. En segundo lugar daré cuenta del desarrollo jurisprudencial de la doctrina del public trust en Estados Unidos desde el siglo XIX hasta nuestros días. A modo de conclusión, analizaré la estructura normativa de la doctrina y su relevancia en el estudio de la idea de propiedad como fideicomiso.

\section{Degradación ambiental y la protección de los bienes comunes}

La protección de los bienes comunes como bosques, prados, ríos, lagos, aguas subterráneas o humedales se ha fundamentado en la pretensión de conservar el conjunto de bienes que proporcionan la existencia material y reproductiva del ser humano. A pesar de que a día de hoy la concepción de la propiedad hegemónica difiera de la idea de propiedad comunal, la columna vertebral del proyecto ecologista ha pasado por la protección de los bienes comunes en beneficio de la mayoría que depende de éstos para subsistir.

Es a partir de la constatación del deterioro del entorno natural, debido al incremento de la producción industrial y del consumo energético, que surge una nueva conciencia ecológica que plantea los límites del crecimiento y del desarrollo tecno-científico. La expansión del modelo económico productivista fundamentado en la entrada de flujos de energía y materiales y en la salida de residuos y emisiones pone en riesgo la estabilidad de los ecosistemas y de la biodiversidad, y provoca daños irreparables como la contaminación de ríos, la pérdida de tierras fértiles, la tala de bosques, la contaminación del aire, la sobrepesca y la acumulación de gases de efecto invernadero. El surgimiento del pensamiento ecológico moderno, durante los años sesenta del siglo pasado, comienza a replantear los ideales de progreso y desarrollo poniendo sobre la mesa los conceptos de límite, riesgo y sostenibilidad. En este contexto, la lucha por los bienes comunes ya no solo se preocupa del cercamiento de áreas comunes sino también de la protección de los ecosistemas que sufren las consecuencias de las externalidades derivadas de los procesos industriales de producción. El desarrollo del pensamiento ecológico moderno y las protestas por los derechos civiles en Estados Unidos condujeron al auge del movimiento por la justicia ambiental (Jaria, 2020, 224-225) que sentó las bases del desarrollo del derecho ambiental. No obstante, a pesar de que desde entonces hasta día de hoy el derecho ambiental ha evolucionado y se ha expandido considerablemente, no ha supuesto un obstáculo para que el desarrollo industrial y tecnológico haya continuado produciendo una degradación ambiental a escala planetaria.

La regulación jurídica ambiental se ha ocupado de la protección de aquellos bienes considerados comunes, pues su protección no puede ser individualizada en favor de un único sujeto (Pettit, 1999, 162); sin embargo, su traducción jurídica ha sido estandarizada dentro de los esquemas tradicionales de los derechos subjetivos. El fracaso de la regulación ambiental 
surgida a partir de los años setenta (Wood, 2009, 54; Mercado, 2013, 140) y el agravamiento gradual de los problemas ambientales, evidenciados en la escasez y el deterioro de los bienes comunes, nos llevan a tener que replantearnos si la protección de este tipo de bienes como derechos subjetivos es eficaz para dar respuesta a los problemas ecológicos a los que nos exponemos. El trasplante de la problemática ambiental al ordenamiento jurídico continúa anclado en un reconocimiento de derechos subjetivos insertos en un conjunto de normas que sustentan un sistema económico que enfatiza los derechos individuales, el desarrollo industrial y el crecimiento económico.

En este sentido, si alejamos el lente de los derechos para estudiar la configuración de los bienes comunes podemos dar cuenta de que la dicotomía público-privado, es insuficiente dentro del esquema de los bienes comunes (Mattei, 2013, 50-51). Mientras, como sostiene Laín $(2018,79)$, la orientación en la protección de los bienes comunes se debe tomar en consideración a partir de una doble dimensión, como bienes asociados con un régimen particular de derechos, y como la dinámica sociopolítica de acción colectiva como medio de gobierno en relación con un recurso, la noción de propiedad vigente está anclada en la tensión entre lo público y lo privado, y ambas responden a una misma lógica económica que busca marginar lo común e implementar un pensamiento único ligado a la acumulación de capital (Mattei, 2013, 65).

Entonces, si nos detenemos a analizar la idea de bienes comunes a partir de una dinámica diferente a la configuración jurídico-política de la propiedad hegemónica, siguiendo a Laín, las dinámicas sociopolíticas de acción colectiva se pueden traducir en una relación entre los beneficiarios -principal- de la protección de los bienes comunes y aquellos en el cargo de gestionarlos -agente-. Esta relación entre agente y principal no solo plantea un conflicto sobre la titularidad de los bienes comunes sino también sobre la función de la propiedad común y los resultados de la gestión por parte del agente. El matiz que diferencia los bienes comunes resulta de sumo interés para el caso que nos ocupa, pues su particularidad no solo radica en la titularidad de estos, sino también en su función. Esta perspectiva por lo tanto plantea que el debate sobre la propiedad no se debe dar solo en torno a la titularidad sino también sobre la función y objetivo que esta tenga dentro de la sociedad. Esto es, si la propiedad debe tener o no una función social independientemente de quién sea su titular.

Los bienes comunes han sido objeto de cercamiento a lo largo de la historia. El continuo proceso de cercamiento y privatización en Estados Unidos durante el siglo XIX reproduce la necesidad expansiva de acumulación propia del sistema capitalista. Este proceso hizo que a mediados de siglo la doctrina del public trust comenzara a tomar relevancia. Desde entonces, como expondré a continuación, la doctrina public trust ha jugado un papel relevante en la protección de los bienes comunes de la explotación y degradación por parte de intereses privados. La estructura normativa que se desarrolla en la doctrina, como se verá, asimila la noción de relación fiduciaria para la administración de los bienes comunes.

\section{La doctrina del public trust en la jurisprudencia estadounidense}

En la doctrina del public trust subyacen los principios reconocidos por el derecho natural romano sobre los bienes comunes: según la ley de la naturaleza, el aire, el agua corriente, el mar y las costas del mar, son bienes comunes. Estos principios, recogidos 
en las Instituciones de Gayo $^{2}$ (Domènech, 2018, 107) fueron recibidos también en Inglaterra tras las luchas de emancipación de los commoners y la subsiguiente promulgación de la Carta Magna y de la Carta Forestal en 1217 (Pisarello, 2011, 40; Mattei, 2013, 50; Domènech, 2018, 108). Sin embargo, el largo proceso de cercamiento durante los siguientes siglos supuso la transformación de los bienes comunes en tierras segmentadas y privatizadas dominadas por la noción de propiedad exclusiva y excluyente del derecho privado romano.

Durante el proceso de cercamiento en Inglaterra, como relata Neeson $(1993,5)$, gran parte de las economías se extinguieron debido a los cercamientos en algún momento entre el siglo XV y el XIX. Puntualiza Linebaugh (2010, 13-14) que en 1688 un cuarto del área total de Inglaterra y Gales era tierra comunal y entre 1725 y 1825 , seis millones de acres de tierra fueron cedidos a terratenientes con influencia política a través de los denominados Enclosure Acts. Así, el ochenta por ciento de la tierra en Inglaterra ya había sido cercada a finales de 1780 (Wordie, 1983, 485-486). Similarmente, en el continente americano los ingleses también llevaron a cabo cercamientos y apropiación privativa de las tierras (Linebaugh y Rediker, 2000, 44). Dinámica que también se extendió a las comunidades indígenas a través del robo, cercado y privatización de sus tierras (Linebaugh, 2008, 246-249).

A partir de esta constante privatizadora que se alargó durante siglos, a mediados del siglo XIX, en un contexto de continua privatización de bienes comunes, a partir de esta doctrina enraizada en el derecho anglosajón y en el derecho natural romano, se recuperan unos principios fundamentales para la salvaguarda del interés común en contraposición del beneficio privado, a través de la relación fiduciaria entre el soberano y el pueblo en la salvaguarda de determinados bienes comunes.

\subsection{La protección de los bienes comunes: la recuperación del public trust}

El primer caso que reflejó la doctrina del public trust fue Arnold v. Mundy ${ }^{3}$, en 1821. El caso dirimía la cuestión sobre los derechos privativos de un terrateniente sobre la pesca en un río situado en los términos de su propiedad. El Tribunal Supremo de Nueva Jersey sentenció que el legislador -el soberano- no podía otorgar ninguna concesión directa y absoluta de las aguas del estado, restringiendo a sus ciudadanos de su derecho común, pues sería un agravio que nunca podría ser soportado por un pueblo libre. Fundamentalmente lo que hace el tribunal es limitar el derecho de propiedad de las aguas navegables, sosteniendo que deben ser protegidas para el beneficio común. Así, establece que ciertos bienes deben permanecer para el beneficio público bajo la figura del fideicomiso público, del que el Estado debe ser el garante. Igualmente, el Tribunal Supremo de Estados Unidos en 1842, en el caso Martin

2 La doctrina mayoritaria coincide en que estos principios se recogen en las Instituciones de Justiniano. Si bien es cierto, cabe mencionar que las Instituciones del Corpus iuris civilis de Justiniano tuvieron en cuenta el trabajo del jurista romano Gayo en el siglo II que, para el caso que nos ocupa, ya daba cuenta de este principio de derecho natural. Cfr. Entre otros: Sax (1970), Scanlan (2000), Underkuffler (2017).

3 Tribunal Supremo de Nueva Jersey: Arnold v. Mundy, 6 N.J.L. 1 (1821). 
v. Waddell ${ }^{45}$, en una disputa sobre la posibilidad de privatizar el derecho a recolectar en las marismas del Río Raritan, sostuvo la argumentación del Tribunal en Arnold v. Mundy. Este caso es central, además porque reconoció que los trece estados originarios eran los sucesores de las prerrogativas que otrora poseía la corona y el parlamento inglés. Por esta razón, las áreas protegidas por el fideicomiso público a partir de entonces estarían bajo la soberanía de los estados 6 .

No obstante, como he avanzado anteriormente, el caso de mayor importancia que supuso un cambio de paradigma en la aplicación de la doctrina fue el caso Illinois Central Railroad v. Illinois ante el Tribunal Supremo en 1892. La cuestión central derivada de este caso fue la constatación de que el public trust, esto es, la conservación y protección de aquellos bienes comunes en beneficio del público, es un atributo propio del soberano al que no puede renunciar y, por lo tanto, el fideicomiso que está bajo la protección de public trust no puede ser enajenado. Estos dos párrafos son muy ilustrativos para comprender la argumentación del tribunal:

"It is a title held in trust for the people of the state that they may enjoy the navigation of the waters, carry on commerce over them and have liberty of fishing therein freed from the obstruction or interference of private parties"

"The decisions are numerous which declare that such property is held by the state, by virtue of its sovereignty in trust for the public. The ownership of the navigable waters of the harbor, and of the lands under them, is a subject of public concern to the whole people of the state. The trust with which they are held, therefore, is governmental, and cannot be alienated" .

En esta sentencia podemos apreciar la estructura de la relación entre soberano y el pueblo. El primero debe conservar en beneficio del segundo dichos bienes para que pueda disfrutar de ellos sin interferencia de intereses privados. Este posicionamiento fue determinante para el desarrollo de la doctrina. A pesar de ello, la aplicación de la doctrina fue diferente en las diferentes jurisdicciones durante las décadas posteriores, pues, aunque se aplicara para garantizar la protección de los derechos de los ciudadanos a acceder a estos bienes, también

4 Tribunal Supremo de Estados Unidos: Martin v. Waddell, 41 U.S. (1842).

5 Críticamente Peter Linebaugh $(2008,192)$ expone que el Juez Taney, ponente de la sentencia, pese a reconocer el interés público de las tierras, utiliza una argumentación jurídica totalmente desprovista de las experiencias, prácticas e ideas de los commoners.

6 En 1845, en el caso Pollard v. Hagan (44 U.S. (3 How.) 212), el Tribunal Supremo amplió el reconocimiento de propiedad estatal de las aguas sumergidas a los futuros estados como sucesores de la Corona Inglesa (Blumm, 2010,8).

7 Illinois Central... Op. cit. páginas 452 y 455: "Es un título en fideicomiso para el pueblo del Estado para que puedan disfrutar de la navegación por las aguas, comerciar sobre ellas y tener la libertad de pescar allí libres de la obstrucción o interferencia de intereses privados".

"En numerosas ocasiones se ha declarado que el Estado, en virtud de su soberanía, posee tal propiedad en fideicomiso para el público. La propiedad de las aguas navegables del puerto y de sus tierras sumergidas, es un asunto de interés público para todo el pueblo del Estado. El fideicomiso por el cual son conservadas es gubernamental y no puede ser enajenado". [Traducción propia]. 
se concibió como una doctrina que respaldaba la promoción del crecimiento económico, del comercio a través de las rutas navegables y de la pesca (Sun, 2011, 572).

Además, en la presente sentencia, a partir de esta relación entre el soberano y el pueblo, el Tribunal también hizo hincapié de forma expresa en la condición contra-mayoritaria de la doctrina. Así lo expresó:

"The position advanced by the railroad company in support of its claim to the ownership of the submerged lands and the right to the erection of wharves, piers and docks at its pleasure, or for its business in the harbor of Chicago, would place every harbor in the country at the mercy of a majority of the legislature of the State in which the harbor is situated"8.

Por lo tanto, el Tribunal, considera que ciertos bienes son inalienables por parte del soberano, y que debido a su condición de fideicomisario no puede enajenarlos y renunciar a sus funciones, y como el legislador no puede enajenarlo, ninguna mayoría parlamentaria podría llegar a hacerlo, porque si lo hiciera, el legislador perdería su condición de fideicomisario. El legislador, por lo tanto, no puede deshacerse de su condición de fideicomisario. En este sentido, al ser el fideicomiso un elemento inherente a la soberanía del Estado, su enajenación supondría, a la vez la enajenación de su soberanía. La doctrina, por lo tanto, prohíbe al legislador restringir su propia soberanía y así protege, consecuentemente, a los que se benefician del bien protegido.

Por lo tanto, la sentencia determina que el public trust funciona como un límite al poder del gobierno en sus funciones, y como un instrumento para asegurar que la protección del bien determinado sea en beneficio de la sociedad en su conjunto.

\subsection{La protección del medio ambiente: una estrategia para el litigio efectivo}

En su seminal artículo, Joseph Sax planteó la viabilidad de utilizar la doctrina del public trust para la protección del medio ambiente y la conservación de los recursos naturales. A partir de la sentencia en Illinois Central, Sax plantea que la doctrina del public trust podría ser un instrumento efectivo para el litigio ambiental. Según Sax, la doctrina no debía limitarse a la aplicación en casos de aguas navegables, sino que debe ampliarse a aquellas situaciones en las que los "intereses públicos difusos" necesiten protección contra "grupos estrechamente organizados con objetivos claros e inmediatos" en una gran variedad de problemas ligados con cuestiones ambientales (Sax, 1970, 556-557). Resulta lógico que la protección del fideicomiso por parte del soberano no sólo sea una obligación negativa. Esto es, que además de una prohibición de enajenar el bien privatizándolo y restringiendo el disfrute de los ciudadanos, el soberano tiene un deber de conservación y protección de dicho bien para que el disfrute pueda ser efectivo. Así lo reconoció el Tribunal Supremo en Illinois Central:

$8 \quad I b$. página 455: "La posición de la compañía ferroviaria en su defensa de la reclamación de la propiedad de las tierras sumergidas y del derecho a la construcción de muelles, embarcaderos y diques a su gusto, o para sus negocios en el puerto de Chicago, colocaría a cada puerto del país a merced de una mayoría de la legislatura del Estado en que se encuentra el puerto". [Traducción propia] 
"The State can no more abdicate its trust over property in which the whole people are interested, like navigable waters and soils under them, so as to leave them entirely under the use and control of private parties, except in the instance of parcels mentioned for the improvement of the navigation and use of the waters, or when parcels can be disposed of without impairment of the public interest in what remains, than it can abdicate its police powers in the administration of government and the preservation of the peace. In the administration of government the use of such powers may for a limited period be delegated to a municipality or other body, but there always remains with the State the right to revoke those powers and exercise them in a more direct manner, and one more conformable to its wishes. So with trusts connected with public property, or property of a special character, like lands under navigable waters, they cannot be placed entirely beyond the direction and control of the State"9.

La publicación de Sax supuso un antes y un después en la aplicación de la doctrina, tanto por la aplicación extensiva de la doctrina, como por su influencia en los poderes legislativos en la elaboración de normas ambientales a través de esta ${ }^{10}$.

En este sentido, influenciados por el artículo de Joseph Sax, en 1979, dos grupos ecologistas demandaron a la ciudad de Los Ángeles por el daño que los desvíos de agua estaban produciendo al ecosistema del Mono Lake. Así, el Tribunal Supremo de California dirimió por primera vez un caso que esgrimía la doctrina del public trust para la protección ambiental. El tribunal dio parcialmente la razón a los grupos ecologistas a través de la aplicación de la doctrina:

"The core of the public trust doctrine is the state's authority as sovereign to exercise a continuous supervision and control over the navigable waters of the state and the lands underlying those waters"11.

La parte demandada se basó en los derechos previamente otorgados por la autoridad competente para la gestión del agua. Por ello, el tribunal reconoció que la agencia encar-

9 Illinois Central... op. cit. páginas 453 - 454: "El Estado no puede abdicar el fideicomiso sobre una propiedad en la que el público tiene intereses, como las aguas navegables y la tierra debajo de ellas, para dejarlas completamente bajo el uso y control de intereses privados, excepto en el caso de las parcelas mencionadas para la mejora de la navegación y uso de las aguas, o cuando las parcelas se pueden eliminar sin menoscabo del interés público, de lo que puede abdicar sus poderes policiales en la administración y preservación del orden público. En su administración, tales poderes pueden delegarse por un período limitado a un municipio u otro organismo, pero el Estado siempre retiene el derecho de revocar esos poderes y ejercerlos de manera más directa, y más conforme a sus deseos. Por lo tanto, los fideicomisos relacionados con propiedad pública, o con propiedad de un carácter especial, como tierras bajo aguas navegables, no pueden alejarse de la dirección y el control del Estado" [Traducción propia].

10 Como curiosidad cabe mencionar que Joseph Sax asesoró en la elaboración del Environmental Protection Act del Estado de Michigan (Sax Act) que fue considerado la primera norma ambiental fundamentada en la doctrina del public trust.

11 Tribunal Supremo de California: National Audubon Society v. Superior Court of Alpine County, página 426 (1983); Conocido popularmente como Mono Lake Case: "El núcleo de la doctrina del public trust es la autoridad del Estado como soberano para supervisar y controlar continuamente las aguas navegables del Estado y las tierras subyacentes a esas aguas". [Traducción propia]. 
gada podía mantener sus derechos privativos siempre y cuando no pusiera en riesgo los ecosistemas del lago. De este modo, a pesar de que la titularidad de la concesión podía permanecer en manos privadas, el interés público del agua y del lago autorizaba al estado, como administrador del fideicomiso, a supervisar el estado de conservación del mismo. Así, el tribunal, al reconocer la fuerza de la doctrina como límite de los derechos privados sobre el agua y los recursos del lago, reconoció que los derechos derivados de una concesión sobre un fideicomiso no pueden derivar en un deterioro del mismo. Consecuentemente, los concesionarios tendrían limitada su capacidad en el manejo y la administración el bien, pues el interés público prevalecería sobre los intereses privados.

La interpretación de Sax, igual que la del tribunal del caso Mono Lake, amplía la aplicación clásica de la doctrina. Esta posición está orientada hacia la necesidad de enarbolar un instrumento jurídico eficaz para proteger los bienes ambientales y los recursos naturales, independientemente del titular del bien. La idea de propiedad común esgrimida en Illinois Central pasaría a un segundo plano, porque, a ojos de Sax, resultará irrelevante quién sea el titular del bien objeto de protección, lo relevante sería que los bienes ambientales sean protegidos en beneficio de la sociedad, independientemente de su titularidad. A partir de aquí, la doctrina del public trust pasó de ser una arcaica doctrina del derecho de propiedad a un principio fundamental del derecho ambiental contemporáneo.

Además de esta influencia vital sobre el derecho ambiental por vía jurisdiccional, el trabajo de Sax influyó de manera decisiva desarrollos legislativos. Más allá de su directa participación en el Michigan Environmental Protection Act en 1970, en los siguientes años, diferentes procesos legislativos se vieron claramente influenciados por su pensamiento. Por ejemplo, la reforma del artículo 27 de la Constitución del Estado de Pensilvania en 1971, establece:

"The people have a right to clean air, pure water, and to the preservation of the natural, scenic, historic and esthetic values of the environment. Pennsylvania's public natural resources are the common property of all the people, including generations yet to come. As trustee of these resources, the Commonwealth shall conserve and maintain them for the benefit of all the people"12.

A pesar de que a día de hoy la doctrina ya no es aplicada como una doctrina propia del derecho de propiedad, todavía, en su aplicación en cuestiones ambientales, podemos observar la relación fiduciaria subyacente a la conservación ambiental. Los bienes ambientales, protegidos bajo el paraguas de la doctrina, son protegidos por parte de un agente que tiene delegada la función por parte de un principal para conservar un bien para el interés común de la sociedad por encima de cualquier interés privado.

Cabe decir que la doctrina continúa aplicándose. De acuerdo con Sun $(2011,578)$, la doctrina se ha aplicado hasta agosto de 2010 en 720 ocasiones, la última vez que el Tribunal

12 Artículo 27 de la Constitución del Estado de Pensilvania: "Las personas tienen derecho a aire limpio, agua pura y a la preservación de los valores naturales, paisajísticos, históricos y estéticos del medio ambiente. Los recursos naturales públicos de Pensilvania son propiedad común de todas las personas, incluidas las generaciones por venir. Como fideicomisario de estos recursos, la Commonwealth los conservará y mantendrá en beneficio de todas las personas". [Traducción propia]. 
Supremo la aplicó fue en el caso Phillips Petroleum Co.v. Mississippi, decidido en 1988, y la última aplicación en un tribunal federal fueron los casos Stockton East Water District v. United States en 2009 y Abbey Co. LLC v. Lexington Insurance Co. en 2008. Como veremos en lo que sigue, la doctrina ha vuelto a ser utilizada recientemente en los llamados litigios climáticos.

\subsection{La protección de la atmósfera: litigio climático y relación intergeneracional}

La constatación de la degradación ambiental de las últimas décadas y la aceleración del calentamiento global, debido al incremento incesante de las emisiones de gases de efecto invernadero, ha hecho que los movimientos sociales y grupos de presión que demandan medidas concretas para hacer frente al cambio climático se hayan multiplicado. Las amenazas que supone el cambio climático son claras pero las acciones, hasta ahora, han sido muy insuficientes. La acumulación de gases de efecto invernadero no cesa y desde la creación del Convenio Marco de Naciones Unidas para el Cambio Climático, las emisiones se han multiplicado ${ }^{13}$. Ante esta tesitura, muchas organizaciones de todo el mundo se han puesto manos a la obra y han acudido a los tribunales para intentar lograr dichas acciones. Una de las acciones llevadas a cabo en Estados Unidos se ha fundamentado en la doctrina del public trust.

En los últimos años han aumentado las actuaciones contra administraciones públicas y empresas privadas en diferentes jurisdicciones para dirimir sus obligaciones con respecto al cambio climático. A través del litigio, los demandantes han solicitado, por un lado, acciones concretas para mitigar las emisiones de gases de efecto invernadero y orientadas a la adaptación al cambio climático y, por otro lado, la atribución de responsabilidades por daños al sistema climático. Entre la creciente casuística alrededor del mundo, en Estados Unidos destaca la denominada Atmospheric Trust Litigation impulsada por la organización ecologista Our Children Trust.

El impulso de esta organización debe mucho al desarrollo doctrinal llevado a cabo por la profesora Mary Christina Wood, quien, en los últimos años, ha promovido los litigios climáticos entorno a la doctrina del public trust y ha defendido la aplicabilidad de la doctrina en la protección de los recursos atmosféricos. Esta perspectiva es heredera de la articulación que en los años ochenta hizo Edith Brown Weiss para el reconocimiento de un fideicomiso planetario para salvaguardar el patrimonio natural y cultural a través del tiempo, y sostener el bienestar de la humanidad (Brown Weiss, 1984, 503).

En este sentido, hasta la actualidad ya han sido presentados veinticinco casos bajo la argumentación de la doctrina del public trust ${ }^{14}$. El primero, Filippone v. Iowa Department of Natural Resources, en el año 2011 y el último, Held v. State of Montana, en el año 2020. La casuística es variada pero la fundamentación central se basa en el reconocimiento de que la doctrina del public trust debe incluir la conservación de la atmósfera. De este modo, al aceptar que la atmósfera está custodiada por el fideicomisario a favor del público, este no

13 Para ser precisos, más de la mitad emisiones a la atmósfera de gases de efecto invernadero procedentes de la quema y uso de combustibles fósiles se han producido a partir de 1988, el mismo año en el que James Hansen, experto climatólogo, testificó ante el Senado de Estados Unidos sobre los efectos del cambio climático.

14 En concordancia con las bases de datos que recogen información sobre los litigios climáticos. En este caso la base de datos del Sabin Centre for Climate Change de la Universidad de Columbia: http://climatecasechart. com/case-category/public-trust-claims/ (Última visita 30 mayo de 2020). 
podría ni dañar, ni dejar que dañasen el bien protegido, pues tendría deberes de conservarlo para el beneficio público. Así, como sí que está ocurriendo, que el daño a la atmósfera es evidente, el fideicomisario no estaría cumpliendo con sus obligaciones. Es por ello, que la reclamación central en estos litigios es la mitigación de emisiones de gases efecto invernadero. Sin embargo, la vital importancia del sistema climático para la estabilidad de todos los ecosistemas, supone que la inacción afectaría también de manera directa otros bienes protegidos bajo la doctrina, por lo que el fideicomisario tendría no solo la obligación de evitar dichos daños, sino también de restaurarlos para que el principal pueda beneficiarse de los recursos en su mejor estado de conservación.

Entre todos los casos presentados hasta la actualidad, el caso que mayor notabilidad ha obtenido es el caso Juliana et. al. v. United States (2015). La demanda, presentada por un grupo de jóvenes y apoyada por diferentes organizaciones ecologistas, alcanzó mucha relevancia pública y jurídica. La demanda fue presentada por un grupo de menores de edad y en nombre de las futuras generaciones, representadas ante el Tribunal por el climatólogo James Hansen. Los demandantes solicitaban la reducción drástica de emisiones de gases de efecto invernadero para el año 2100, con la intención de salvaguardar la estabilidad del sistema climático, como la condición de necesidad para proteger el derecho a la vida, a la libertad, y a la propiedad de los demandantes en el futuro. De este modo, el grupo de menores argumentó que, si las concentraciones de gases de efecto invernadero continúan aumentando, los derechos humanos de aquellos que habitarán la tierra en el futuro están en riesgo. Para todo ello, los demandantes sostuvieron que la nación, como agente fideicomisario, debe proteger la atmósfera en beneficio de las presentes y las futuras generaciones.

Así, el argumento que estructura este tipo de litigio es el mismo que en los litigios ambientales. Sin embargo, los demandantes hacen hincapié en el interés perpetuo del público sobre los bienes en fideicomiso. Mientras el bien sea inalienable, como lo es bajo la doctrina del public trust, el fideicomisario debe llevar a cabo su función de protección y conservación para que los interesados en la actualidad y en el futuro puedan beneficiarse del bien protegido por el fideicomiso. El daño causado por las emisiones de gases de efecto invernadero sobre la atmósfera no es inmediato, por ello, el agente debería actuar preventivamente para no incumplir sus obligaciones como fideicomisario en relación a aquellos beneficiados, sea en la actualidad o en el futuro.

Los resultados de la aplicación de la doctrina del public trust en los litigios climáticos hasta día de hoy no son muy halagüeños. A pesar de ello, resulta de sumo interés la configuración de la relación fiduciaria presente en esta doctrina para continuar exigiendo responsabilidades ante el cambio climático a aquellos que tienen el deber de proteger los bienes comunes en beneficio del interés general.

\section{Conclusión}

La aplicación de esta doctrina tiene mucha relevancia a la hora de analizar los derechos de propiedad como una relación fiduciaria entre agente y principal. El razonamiento judicial, desde su primera aplicación a mediados del siglo XIX, hasta la argumentación de los demandantes en los litigios climáticos, se fundamenta en la necesidad de que el agente conserve un bien en beneficio del principal. A pesar de que las motivaciones para su aplicación han 
cambiado a lo largo del tiempo y se han adaptado a las circunstancias de cada época, su estructura sigue intacta.

Así, por ejemplo, si consideramos que un lago es de interés público y está protegido por la doctrina del public trust para que el pueblo pueda acceder a pescar y obtener recursos hídricos, sería difícil justificar que la obligación del agente se limitara a una obligación negativa de no enajenar el bien. La conservación del mismo es central para que el principal se pueda beneficiar de este de manera efectiva. Por ello, las obligaciones del agente deben ser extendidas para poder llevar a cabo su función principal: la conservación y protección del bien.

De todo lo anterior, resulta evidente que en la doctrina del public trust subyace una estructura fiduciaria entre aquellos que poseen en común los bienes y el encargado de custodiarlos, que deberá cumplir sus funciones para que el principal pueda realmente beneficiarse de los bienes. Por ello, el vínculo entre agente y principal, no autoriza al agente a conservar el bien de manera discrecional, pues el interés del principal está en el centro de la estructura de gobierno. Así, el agente no solo deberá proteger el bien, sino que deberá hacerlo en virtud de una obligación de garantizar al principal su acceso a dichos bienes en estado óptimo de conservación.

Esta doctrina supone una herramienta de protección y conservación de los bienes comunes que va más allá de las estrategias fundamentadas en lo derechos subjetivos, y que integra la concepción de propiedad fiduciaria como forma de gobierno de dichos bienes.

\section{Referencias}

Blumm, M. C. (2010), «The Public Trust Doctrine and Private Property: The Accommodation Principle», Pace Environmental Law Review, Vol. 27, pp. 649-666.

Brown Weiss, E. (1984), «The Planetary Trust: Conservation and Intergenerational Equity», Ecology Law Quarterly, Vol. 11, 4, pp. 495-582.

Domènech, A. (2018), «Dominación, derecho, propiedad y economía política popular (Un ejercicio de historia de los conceptos)», Escritos Sin Permiso: https://www.sinpermiso. info/textos/antoni-domenech-1952-2017-libro-de-sin-permiso (última consulta, 30 de mayo de 2020).

Jaria, J. (2020), La Constitución del Antropoceno, Valencia: Tirant Humanidades.

Kaplan, I. (2012), «Does the Privatization of Publicly Owned Infrastructure Implicate the Public Trust Doctrine? Illinois Central and the Chicago Parking Meter Concession Agreement», Northwestern Journal of Law \& Social Policy, Vol. 7, 1, Article 5, pp. 136-169.

Klass, A. B. (2015), «The Public Trust Doctrine in the Shadow of State Environmental Rights Laws: A Case Study», Environmental Law, Vol. 45, pp. 431-462.

Laín, B. (2018), «Common property and (pre)distributive justice», Oxímora Revista Internacional de Ética y Política, Vol. 12, pp. 72-88.

Linebaugh, P. y Rediker, M. (2000), The Many-Headed Hydra: Sailors, Slaves, Commoners, and the Hidden History of the Revolutionary Atlantic, Boston: Beacon Press.

Linebaugh, P. (2008), The Magna Carta Manifesto: Liberties and Commons for All, Berkeley and Los Angeles, California: University of California Press. 
Linebaugh, P. (2010), «Enclosures from the Bottom Up», Radical History Review, Issue 108, pp. 11-27.

Mattei, B. (2013), Bienes comunes. Un manifiesto, traducción de G. Pisarello, Madrid: Trotta.

Mercado, P. (2013), «Derechos insostenibles», en Estévez, J.A. (ed.): El libro de los deberes: las debilidades e insuficiencias de la estrategia de los derechos, Madrid: Trotta, pp. 139-166.

Mundó, J. (2017), «La constitución fiduciaria de la libertad política. (Por qué son importantes las coyunturas interpretativas en la filosofía política)», Isegoría. Revista de Filosofía Moral y Política, Vol. 57, pp. 433-454.

Mundó, J. (2018), «De la retórica absolutista de la propiedad al sentido común de la propiedad limitada», Sin Permiso: República y socialismo también para el siglo XXI, n. 16, pp. 35-64.

Neeson, J. M. (1993), Commoners: common right, enclosure and social change in England, 1700-1820, New York: Cambridge University Press.

Pettit, P. (1999), Republicanismo: una teoría sobre la libertad y el gobierno, traducción de A. Domènech, Barcelona: Paidós.

Pisarello, G. (2011), Un largo termidor. La ofensiva del constitucionalismo antidemocrático, Madrid: Trotta.

Sax, J. (1970), «The Public Trust Doctrine in Natural Resource Law: Effective Judicial Intervention», Michigan Law Review, Vol. 68, pp. 471-566.

Scanlan, M. K. (2000), «The Evolution of the Public Trust Doctrine and the Degradation of Trust Resources: Courts, Trustees and Political Power in Wisconsin», Ecology Law Quarterly, Vol. 27, 135, pp. 135-214.

Sun, H. (2011), «Toward a New Social-Political Theory of the Public Trust Doctrine», Vermont Law Review, Vol. 35, pp. 563-622.

Underkuffler, L. S. (2017), «Property, Sovereignty, and the Public Trust», Theoretical Inquiries in Law», Vol. 18, 2, pp. 329-353.

Wood, M. C. (2009), «Advancing the Sovereign Trust of Government to Safeguard the Environment for Present and Future Generations (Part I): Ecological Realism and the Need for a Paradigm Shift», Environmental Law, Vol. 39, pp. 43-89.

Wordie, J. R. (1983), «The Chronology of English Enclosure: 1500 - 1914», The Economic history Review Second Series, Vol. 36, 4, pp. 483-505. 
